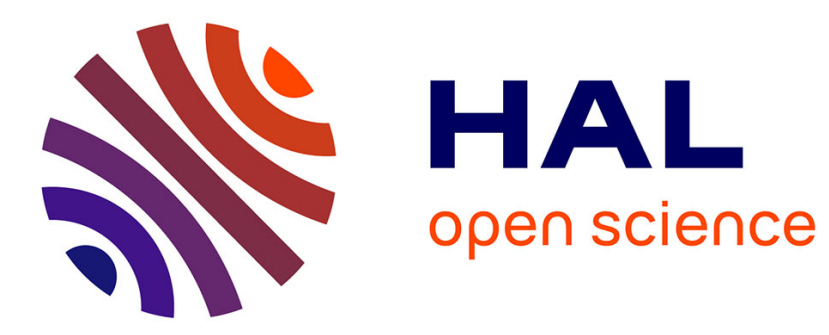

\title{
Using MALDI-TOF MS to identify mosquitoes collected in Mali and their blood meals
}

Fatalmoudou Tandina, Sirama Niare, Maureen Laroche, Abdoulaye K. Kone, Adama Z. Diarra, Abdoulaye Ongoiba, Jean Michel Berenger, Ogobara K. Doumbo, Didier Raoult, Philippe Parola

\section{To cite this version:}

Fatalmoudou Tandina, Sirama Niare, Maureen Laroche, Abdoulaye K. Kone, Adama Z. Diarra, et al.. Using MALDI-TOF MS to identify mosquitoes collected in Mali and their blood meals. Parasitology, 2018, 145 (9), pp.1170-1182. 10.1017/S0031182018000070 . hal-01910310

\section{HAL Id: hal-01910310 https://hal.science/hal-01910310}

Submitted on 9 Apr 2019

HAL is a multi-disciplinary open access archive for the deposit and dissemination of scientific research documents, whether they are published or not. The documents may come from teaching and research institutions in France or abroad, or from public or private research centers.
L'archive ouverte pluridisciplinaire HAL, est destinée au dépôt et à la diffusion de documents scientifiques de niveau recherche, publiés ou non, émanant des établissements d'enseignement et de recherche français ou étrangers, des laboratoires publics ou privés. 
See discussions, stats, and author profiles for this publication at: https://www.researchgate.net/publication/322991270

\section{Using MALDI-TOF MS to identify mosquitoes collected in Mali and their blood} meals

Article in Parasitology · February 2018

DOI: $10.1017 / 50031182018000070$

CITATIONS

10 authors, including:

Fatalmoudou Tandina

Aix-Marseille Université

9 PUBLICATIONS 24 CITATIONS

SEE PROFILE

130

Maureen Laroch

IHU Méditerranée Infection

17 PUBLICATIONS 62 CITATIONS

SEE PROFILE

Some of the authors of this publication are also working on these related projects:

Identification of arthropod vectors by MALDI-TOF MS View project

cimex population morphology View project

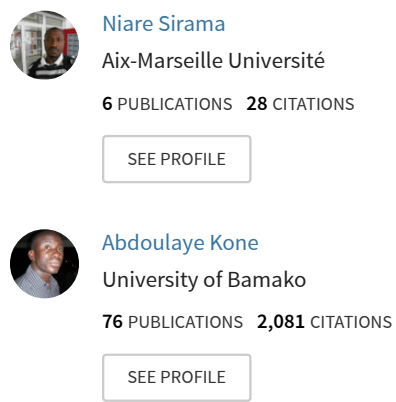




\section{cambridge.org/par}

\section{Research Article}

Cite this article: Tandina F et al. Using MALDITOF MS to identify mosquitoes collected in Mali and their blood meals. Parasitology https://doi.org/10.1017/S0031182018000070

Received: 15 July 2017

Revised: 19 December 2017

Accepted: 21 December 2017

\section{Key words:}

MALDI-TOF MS; mosquito; field; blood meals; Whatman; Mali

\section{Author for correspondence:}

Philippe Parola, Email: philippe.parola@univamu.fr

\section{Using MALDI-TOF MS to identify mosquitoes collected in Mali and their blood meals}

\author{
Fatalmoudou Tandina ${ }^{1,2}$, Sirama Niaré1,2, Maureen Laroche ${ }^{1}$, \\ Abdoulaye K Koné2, Adama Z Diarra ${ }^{1,2}$, Abdoulaye Ongoiba², \\ Jean Michel Berenger ${ }^{1}$, Ogobara K Doumbo², Didier Raoult ${ }^{1}$ and Philippe Parola ${ }^{1}$
}

${ }^{1}$ Aix Marseille Univ, IRD, AP-HM, IHU-Méditerranée Infection, SSA, VITROME, Marseille, France and ${ }^{2}$ Department of Epidemiology of Parasitic Diseases, Malaria Research and Training Center, University of Science, Techniques and Technologies of Bamako, Mali

\begin{abstract}
Matrix-assisted laser desorption/ionization time-of-flight mass spectrometry (MALDI-TOF MS) has been recently described as an innovative and effective tool for identifying arthropods and mosquito blood meal sources. To test this approach in the context of an entomological survey in the field, mosquitoes were collected from five ecologically distinct areas of Mali. We successfully analysed the blood meals from 651 mosquito abdomens crushed on Whatman filter paper (WFPs) in the field using MALDI-TOF MS. The legs of 826 mosquitoes were then submitted for MALDI-TOF MS analysis in order to identify the different mosquito species. Eight mosquito species were identified, including Anopheles gambiae Giles, Anopheles coluzzii, Anopheles arabiensis, Culex quinquefasciatus, Culex neavei, Culex perexiguus, Aedes aegypti and Aedes fowleri in Mali. The field mosquitoes for which MALDI-TOF MS did not provide successful identification were not previously available in our database. These specimens were subsequently molecularly identified. The WFP blood meal sources found in this study were matched against human blood $(n=619)$, chicken blood $(n=9)$, cow blood $(n=9)$, donkey blood $(n=6)$, dog blood $(n=5)$ and sheep blood $(n=3)$. This study reinforces the fact that MALDI-TOF MS is a promising tool for entomological surveys.
\end{abstract}

\section{Introduction}

Mosquito-borne infectious diseases are a public health concern in tropical countries, and an emerging problem in temperate areas (Becker et al. 2010). The main mosquito vectors, which may transmit pathogens during their blood meals, belong to three main genera, namely Aedes, Culex and Anopheles (Becker et al. 2010). Aedes spp. mosquitoes are vectors for several arboviruses including the Yellow Fever, Dengue, Chikungunya and Zika viruses, which have come to the world's attention in recent years (Gardner and Ryman, 2010; Vasilakis et al. 2011; Caglioti et al. 2013). Culex mosquitoes are responsible for West Nile Virus (WNV) and Japanese encephalitis virus transmission around the world (Komar, 2003; Anosike et al. 2005; de Wispelaere et al. 2017). Anopheles mosquitoes are the primary vectors of malaria. Female Anopheles mosquitoes are able to transmit six species of Plasmodium to humans: $P$. falciparum, $P$. vivax, P. malariae, $P$. ovale wallikeri, $P$. ovale curtisi, $P$. knowlesi and P. simium (WHO, 2016; Brasil et al. 2017). Malarial transmission remains high in Africa, with 117886 deaths in 2015 (WHO, 2016). In Mali, West Africa, 1544 deaths were recorded as being attributable to malaria in 2015 (WHO, 2016). It is reasonable to assume that the number of malaria-associated deaths remains underestimated.

The precise identification of mosquito fauna is essential in entomological surveys, and in order to plan control measures and monitor their impact (Bass et al. 2007). Furthermore, the identification of mosquito blood meal sources is essential to understanding the biting behaviour of mosquito vectors (anthropophilic or zoophilic) (Muturi et al. 2013).

Mosquitoes are most frequently identified at the genus and species levels by morphological characteristics and using molecular tools. Morphological identification requires well-trained entomologists using dichotomous identification keys (Gillies MT 1987). Morphological identification continues to be the standard approach for arthropod studies. However, it presents some limits in terms of discriminating cryptic or sibling species. In recent years, molecular tools have emerged and can identify mosquitoes by amplifying different target genes. The target gene, such as the cytochrome $c$ oxidase (COI), internal transcribed spacer 2, IGS regions of rDNA, has been used to satisfactorily identify mosquitoes up to sibling species with great specificity and sensitivity (Folmer et al. 1994).

Several approaches have been developed to identify the host vertebrate blood source of mosquito meals. The main tools include a serological approach which involves precipitin tests and enzyme-linked immunosorbent assays (ELISA) (Fyodorova et al. 2006; Gomes et al. 2013). However, these techniques present several limitations, including the availability of specific antisera against a broad diversity of host species and the cross-reactivity of antibodies for close species. To this end, molecular methods have also been developed to identify

\section{CAMBRIDGE UNIVERSITY PRESS}


mosquito blood meal sources, such as mammalian blood and avian blood from Culex pipiens complex (Gomes et al. 2013). However, molecular methods also present several constraints, such as their cost, the time they take and the need for bulky equipment.

Matrix-assisted laser desorption/ionization time-of-flight mass spectrometry (MALDI-TOF MS) has recently been used as an alternative tool for rapid arthropod identification. The mass spectrum from a new sample, generated using MALDI-TOF MS, is compared with a library of spectra from a reference database. In our laboratory, the MALDI-TOF MS approach has been routinely used to identify arthropods such as ticks (using their legs) (Yssouf et al. 2013, 2015; Kumsa et al. 2016), fleas (bodies of fleas without the abdomen) (Yssouf et al. 2014b), sand flies (using their thoraces, wings and legs) (Lafri et al. 2016), adult mosquitoes (using their legs) (Yssouf et al. 2013, 2014a) and mosquito larvae (using whole mosquitoes) (Dieme et al. 2014). Preliminary studies have also reported that MALDI-TOF MS may be used for mosquito blood meal identification. When the MS spectra obtained from the abdomen of mosquitoes which had been experimentally engorged on different blood meals source were tested, the MS protein profiles were clearly distinct according to the origin of the mosquito blood meals, up to $24 \mathrm{~h}$ post-feeding (Niare et al. 2016). During entomological surveys, it may be difficult to preserve samples, and entomologists frequently use Whatman filter papers (WFPs) to preserve mosquito blood meals in the field by crushing the engorged abdomens onto WFPs.

In this study, the goal was to use the proteomic MALDI-TOF MS approach to identify mosquitoes collected in Mali and determine the sources of their blood meals. For this purpose, mosquitoes were collected in different ecological areas of Mali and tested by MALDI-TOF MS in Marseille, France. The abdomens of engorged female mosquitoes were crushed onto WFP to determine the blood meal sources using MALDI-TOF MS.

\section{Materials and methods}

\section{Ethics statement}

Consent was obtained from the heads of families where the mosquitoes were collected. Ethical approval for the collection of mosquito was granted by authorities from the National Malaria Control Program (NMCP) and approved by the Faculty of Medicine Ethical Committee, Bamako, Mali (No2016/113/CE/ FMPOS). The mosquito samples were processed and stored in line with the World Health Organization (WHO) Good Laboratory Practices guidance and documents on mosquito sampling handling procedures.

\section{Collection sites}

This study was conducted in three different localities in Mali, namely Donéguébougou, Bougoula-hameau and Bamako. In Bamako, the collection was performed in the three semi-urban areas of Sotuba, Yirimadio and Missabougou. The geo-positions of each collection site are as follows: Bougoula-hameau $\left(-5^{\circ}\right.$ $\left.66^{\prime} 13.1^{\prime \prime}, 11^{\circ} 30^{\prime} 95.2^{\prime \prime} \mathrm{E}\right)$; Donéguébougou $\left(-7^{\circ} 98^{\prime} 39.8^{\prime \prime} \mathrm{N}, 12^{\circ}\right.$ $\left.80^{\prime} 44.9^{\prime \prime} \mathrm{E}\right)$ and the semi-urban areas of Bamako, Sotuba $\left(-9^{\circ}\right.$ $\left.18^{\prime} 65.7^{\prime} \mathrm{N}, 8^{\circ} 23^{\prime} 07.4^{\prime} \mathrm{E}\right)$, Yirimadio $\left(-9^{\circ} 18^{\prime} 56.5^{\prime} \mathrm{N}, 6^{\circ} 23^{\prime} 01.8^{\prime \prime} \mathrm{E}\right)$ and Missabougou $\left(-9^{\circ} 18^{\prime} 77.5^{\prime \prime} \mathrm{N}, 8^{\circ} 23^{\prime} 03.9^{\prime \prime} \mathrm{E}\right)$.

\section{Mosquito collection}

Mosquitoes were collected from the various sites during the middle of the rainy season between July and August 2016 (WHO,
1992). The peak densities and consequentially of anopheline mosquitoes in Mali occur in August (Sogoba et al. 2007). Mosquitoes were collected over three consecutive days per week. On each day, mosquitoes were aspirated from 10 houses using a mouth aspirator (Model 612, John W Hock, Gainesville, Florida, USA). All mosquitoes were collected indoors in the morning between 8 am and noon. The mosquito specimens were identified using morphological criteria (Gillies MT 1987). After being collected, mosquito specimens were kept at room temperature (RT) between 2 and $4 \mathrm{~h}$ during the female abdomens crushed process and then were stored at $-20^{\circ} \mathrm{C}$. Each mosquito specimen was then individually transferred to a $1.5 \mathrm{~mL}$ Eppendorf tube labelled with a reference number, the gender of the specimen, the date and site of collection.

Mosquito abdomens with visible blood meals were crushed on WFPs (Whatman International Ltd., Maidstone, England, approved by BSI). Following the entomological stage, all samples were transported to Aix-Marseille University for mosquito and blood meal identification using MALDI-TOF MS in September and October 2016.

\section{Preparation of samples for MALDI-TOF MS analysis}

\section{Mosquito identification}

The legs of the specimens were cleaned in $70 \%(\mathrm{v} / \mathrm{v})$ ethanol for between one to two minutes, then rinsed in high performance liquid chromatography (HPLC) grade water. The legs from each mosquito were individually placed in $1.5 \mathrm{~mL}$ Eppendorf tubes with glass powder (Sigma, Lyon, France), $15 \mu \mathrm{L}$ of $70 \%$ (v/v) formic acid (Sigma, Lyon, France), and $15 \mu \mathrm{L}$ of $50 \%$ (v/v) acetonitrile (Fluka, Buchs, Switzerland). The samples were crushed using a TissueLyser device (Qiagen, Hilden, Germany) over three cycles of $30 \mathrm{~m} \mathrm{~s}^{-1}$ for $60 \mathrm{~s}$ (Nebbak et al. 2016). The samples were centrifuged at $200 \mathrm{~g}$ for one minute, and $1.5 \mu \mathrm{L}$ of supernatant of each homogenate was deposited on the MALDI-TOF target plate in quadruplicate (Bruker Daltonics, Wissembourg, France) and covered with $1.5 \mu \mathrm{L}$ of CHCA matrix solution composed of saturated $\alpha$-cyano-4-hydroxycynnamic acid (Sigma, Lyon, France), 50\% acetonitrile (v/v), 2.5\% trifluoroacetic acid (v/v) (Aldrich, Dorset, UK), and HPLC grade water (Yssouf et al. 2013; Nebbak et al. 2016). The target plate was dried for several minutes at RT and placed in the Microflex LT MALDI-TOF Mass Spectrometer (Bruker Daltonics, Wissembourg, France) for analysis (Yssouf et al. 2013, 2016; Nebbak et al. 2016).

\section{Bloody Whatman filter papers (BWFPS)}

A piece of the WFPs (i.e. about $1 \mathrm{~mm}^{2}$ ) containing crushed abdomens from engorged mosquitoes was individually cut using a sterile scalpel and transferred to a new $1.5 \mathrm{~mL}$ Eppendorf tube (Niare et al. 2017). For each piece of WFPs, $20 \mu \mathrm{L}$ of formic acid $(70 \%, \mathrm{v} / \mathrm{v})$ plus $20 \mu \mathrm{L}$ of acetonitrile (50\% v/v) (Fluka, Buchs, Switzerland) was added and incubated for $10 \mathrm{~min}$ at RT. After a fast spin (i.e. $10000 \mathrm{rpm}$ for $20 \mathrm{~s}$ ), $1 \mu \mathrm{L}$ of the supernatant of each sample was loaded onto the MALDI-TOF target plate in quadruplicate and covered with $1 \mu \mathrm{L}$ of CHCA matrix (Niare et al. 2016). After drying for several minutes at RT, the MALDI-TOF target plate was placed in the Microflex LT MALDI-TOF Mass Spectrometer (Bruker Daltonics, Bremen, Germany) for analysis. To control loading on mass spectra steel, matrix quality and MALDI-TOF apparatus performance, the matrix solution was loaded in duplicate onto each MALDI-TOF plate with or without a bacterial test standard (Bruker protein Calibration Standard I) (Niare et al. 2016). 


\section{Spectral analysis}

Protein mass profiles were acquired using a Microflex LT MALDI-TOF Mass Spectrometer, with detection in the linear positive-ion mode at a laser frequency of $50 \mathrm{~Hz}$ within a mass range of $2-20 \mathrm{kDa}$. The acceleration voltage was $20 \mathrm{kV}$, and the extraction delay time was $200 \mathrm{~ns}$. Each spectrum corresponded to ions obtained from 240 laser shots performed in six regions of the same spot and automatically acquired using the AutoXecute of the Flex Control v.2.4 software (Bruker Daltonics, Bremen, Germany). The spectrum profiles obtained from mosquito legs and bloody WFPs were visualized with Flex analysis v.3.3 software and were exported to ClinProTools version v.2.2 (Bruker Daltonics, Bremen, Germany) and MALDI-Biotyper v.3.0. (Bruker Daltonics, Bremen, Germany) for data processing (smoothing, baseline subtraction, peak picking) and evaluated using cluster analysis. Spectra of low quality were excluded from the study.

\section{MALDI-TOF identification of mosquitoes}

We used our in-lab arthropod MALDI-TOF database, which includes spectra obtained from various arthropods listed in Table 1. The database was upgraded with the spectra of three Culex quinquefasciatus mosquitoes and one Culex neavei mosquito collected and molecularly identified during this study. A comparison of the spectrum of each specimen of mosquito legs from Mali was evaluated against the home-made MS reference spectra database using the MALDI-Biotyper software v3.0. tool (Bruker Daltonics, Bremen, Germany). The level of significance was determined using the log score values (LSVs) provided by the MALDI-Biotyper software v.3.3. corresponding to a matched degree of signal intensities of mass spectra of the query and the reference spectra. LSVs ranged from zero to three. To determine the origin of blood meals, MALDI-TOF MS spectra from the abdominal proteins of engorged mosquitoes crushed on WFPs were also blindly queried against the database. A sample was considered to be correctly and significantly identified at the species level when the queried spectrum had a log score value (LSV) $\geqslant 1.8$ (Niare et al. 2016).

\section{Cluster analysis}

Cluster analysis on MSP (MSP, Main Spectrum Profile) spectra was performed and the comparison of the main spectra given by the MALDI-Biotyper software was clustered according to protein mass profile (i.e. their mass signals and intensities). We performed hierarchical clustering of the mass spectra of two specimens per mosquito species using the MSP dendrogram function. The clustering analyses were performed to visualize the homogeneity level of MS spectra from specimens belonging to the same species level. The resulting MSP dendrogram shows how samples are related to one another.

\section{Molecular identification}

A molecular tool was used to confirm MALDI-TOF MS identification in randomly selected mosquitoes. Molecular identification was also conducted for specimens whose spectra did not match with any mosquito spectrum in our database. When it was demonstrated that a high quality spectrum had been obtained from a mosquito species missing from our database, this new spectrum was added to the database. DNA extractions from individual mosquito heads and thorax samples were performed using the EZ1 DNA Tissue Kit (Qiagen, Hilden, Germany) according to the manufacturer's recommendations. A set of primers specifically amplifying a fragment of $710 \mathrm{bp}$ of the mosquito's cytochrome $c$ oxidase I gene (mCOI) was used (LCO1490 (forward): 5'-GGTCAAC

Table 1. List of the arthropod species present in our home-made MALDI-TOF MS ${ }^{\mathrm{a}}$ database.

\begin{tabular}{|c|c|}
\hline Mosquitoes & $\begin{array}{l}\text { Imago: Aedes albopictus, Ae. excrucians, Ae. vexans, Ae. rusticus, Ae. dufouri, Ae. cinereus, Ae. fowleri, Ae. } \\
\text { aegypti, Ae. caspius, Anopheles gambiae Giles, An. coluzzii, An. funestus, An. ziemanni, An. arabiensis, An. } \\
\text { wellcomei, An. rufipes, An. pharoensis, An. coustani, An. claviger, An. hyrcanus, An. maculipennis, Culex } \\
\text { quinquefasciatus, Cx. pipiens, Cx. modestus, Cx. insignis, Cx. neavei, Mansonia uniformis, Culiseta } \\
\text { longiareolata, Orthopodomyia reunionensis, Coquillettidia richiardii and Lutzia tigripes. } \\
\text { Larvae: Aedes aegypti, Ae. albopictus, Anopheles gambiae Giles, An. coluzzii, Cx. pipiens, Cx. molestus, } \\
\text { Culiseta sp. }\end{array}$ \\
\hline Sand flies & $\begin{array}{l}\text { Phlebotomus papatasi, } P \text {. (Larrousius) longicuspis, } P \text {. (Larrousius) perfiliewi, } P \text {. (Larrousius) perniciosus, } P \text {. } \\
\text { (Paraphlebotomus) sergenti and Sergentomyia minuta }\end{array}$ \\
\hline Triatomines & $\begin{array}{l}\text { Triatoma infestans, Rhodnius prolixus, Rh. pictipes, Rh. robustus, Eratyrus mucronatus and Panstrongylus } \\
\text { geniculatus }\end{array}$ \\
\hline Ticks & $\begin{array}{l}\text { Legs: Amblyomma cohaerens, Am. gemma, Am. variegatum, Dermacentor marginatus, D. reticulatus, } \\
\text { Haemaphysalis leachi, Hae. concinna, Hae. spinulosa, Hyalomma marginatum rufipes, H. truncatum, H. } \\
\text { detritum, Rhipicephalus decoloratus, Ixodes hexagonus, I. ricinus, Rh. bergeoni, Rh. e. evertsi, } \\
\text { Rh. praetextatus, Rh. pulchellus, Rh. sanguineus, Rh. sulcatus, Rh. microplus, Rh. annulatus, Rh. turanicus } \\
\text { and Rh. bursa. } \\
\text { Hemolymph: Am. variegatum, D. marginatus, H. marginatum rufipes, Rh. bursa and Rh. sanguineus. }\end{array}$ \\
\hline Mites & Leptotrombidium chiangraiensis, L. imphalum and L. deliense \\
\hline Bedbugs & Cimex lectularius \\
\hline Lice & $\begin{array}{l}\text { Pediculus humanus, Damalinia bovis, D. caprae, D. ovis, Haematopinus eurysternus, Linognatus vituli and } L \text {. } \\
\text { africanus }\end{array}$ \\
\hline Fleas & Ctenocephalides felis, Ct. canis, Archaeopsylla erinacei, Xenopsylla cheopis and Stenoponia tripectinata \\
\hline Abdomen of mosquitoes engorged & $\begin{array}{l}\text { Anopheles gambiae Giles fed on: Homo sapiens, Equus caballus, Ovis aries, rabbit, Balb/C mouse, Rattus } \\
\text { norvegicus, Canis familiaris, Bos taurus, Capra hircus, Gallus gallus, Equus asinus, Tapirus indicus, Tapirus } \\
\text { terrestris, Carollia perspicillata, Thraupis episcopus, Erythrocebus patas and Callithrix pygmaea blood } \\
\text { Aedes albopictus fed on: Homo sapiens blood }\end{array}$ \\
\hline $\begin{array}{l}\text { Anopheles gambiae Giles blood meals from } \\
\text { Whatman Filter paper }\end{array}$ & Ovis aries and Homo sapiens blood \\
\hline
\end{tabular}

${ }^{a}$ MALDI-TOF MS, matrix-assisted laser desorption/ionization time-of-flight mass spectrometry. 
AAATCATAAGATATTGG-3'; HC02198 (reverse): 5'-TAAAC TTCAGGGTGACCAAAAAATCA-3' (Folmer et al. 1994). We used gene Acetylcholinesterase-2 to amplify a fragment of 610 bp of Culex pipiens and a fragment of 274 bp of Cx. quinquefasciatus. The primers set were ACEquin (forward): $5^{\prime}$-CCTT CTTGAATGG CTGTGGCA-3', ACEpip (forward): 5'-GGAAA CAACGACGTATGTACT-3', B1246s (reverse): 5'-TGGAGCC TCCTCTTCACGGC-3' (Smith and Fonseca, 2004).

A set of primers specifically amplifying a fragment of $310 \mathrm{bp}$ of the Anopheles gambiae mosquito complex Acomplex_28S_MBF 5'-AGCKCGTCTTGGTCTGGGG-3' and Acomplex_28S_MBR $5^{\prime}$-GCCGACAAGCTCAYTAGTGT-3' was designed in our laboratory based on the work by Fanello et al. and PCR reactions were processed as described (Fanello et al. 2002). Molecular identification of the blood was carried out on the bloody WFPs from 41 specimens randomly selected from the Malian samples, as previously described (Niare et al. 2016). Positive PCR products were then purified and sequenced using the same primers with the BigDye version 1-1 Cycle Sequencing Ready Reaction Mix (Applied Biosystems, Foster City, CA) and an ABI 3100 automated sequencer (Applied Biosystems, Foster City, CA). The sequences were assembled and analyzed using the ChromasPro software (version 1.34) (Technelysium Pty. Ltd., Tewantin, Australia) and the NCBI BLAST website (http://blast.ncbi.nlm.nih.gov).

\section{Results}

\section{Identification of the mosquitoes by MALDI-TOF MS}

A total of 865 mosquitoes were captured by aspiration in Mali from various collection sites, including 257 in Bougoula-hameau,
168 in Donéguébougou, 230 in Sotuba, 125 in Missabougou and 85 in the Yirimadio semi-urban zones of Bamako (Fig. 1). All specimens collected were morphologically identified to genus level as Anopheles spp. (287/865; 33.18\%), Culex spp. (573/865; 66.24\%) and Aedes spp. (5/865;0.58\%).

For MALDI-TOF analysis, MS spectra of good quality were obtained from 272 legs of Anopheles spp. Of these 272 Anopheles spp. tested against the arthropod MS database, 97\% ( $n=264 / 272)$ were identified with a log score value (LSV) ranging between 1.70 and 2.575. These 264 Anopheles specimens were identified as Anopheles gambiae Giles (95.80\%, $n=253 / 264)$, Anopheles coluzzii $(3.40 \%, n=9 / 264)$ and Anopheles arabiensis $(0.80 \%, n=2 / 264)$ (Fig. 2) by MALDI TOF MS. The remaining eight Anopheles spp. were subjected to molecular identification.

We tested the MS spectra from the legs of 549 Culex spp. against our arthropod database.

Of these 549 Culex spp. high-quality spectra, $98 \%(n=537 / 549)$ were identified as species contained in our database. The 537 Culex specimens were identified by MALDI-TOF MS as Cx. quinquefasciatus $(98 \%, n=527 / 537)$ and $C x$. neavei $(2 \%, n=10 / 537)$ from Mali (Fig. 3). These 537 Culex obtained LSVs ranging from 1.713 to 2.611 . The remaining twelve Culex spp. were subjected to molecular identification.

The five Aedes specimens were identified by MALDI-TOF MS as Aedes fowleri $(n=4)$ and Aedes aegypti $(n=1)$, with log score values ranging between 2.128 and 2.418 .

The MS spectra comparison from different mosquito species with Flex analysis software revealed an intra-species reproducibility and an inter-species specificity (Fig. 4). Visually, the signals and intensity of mosquito species' protein profiles (Fig. 4) were consistent for MALDI-TOF identification and revealed eight

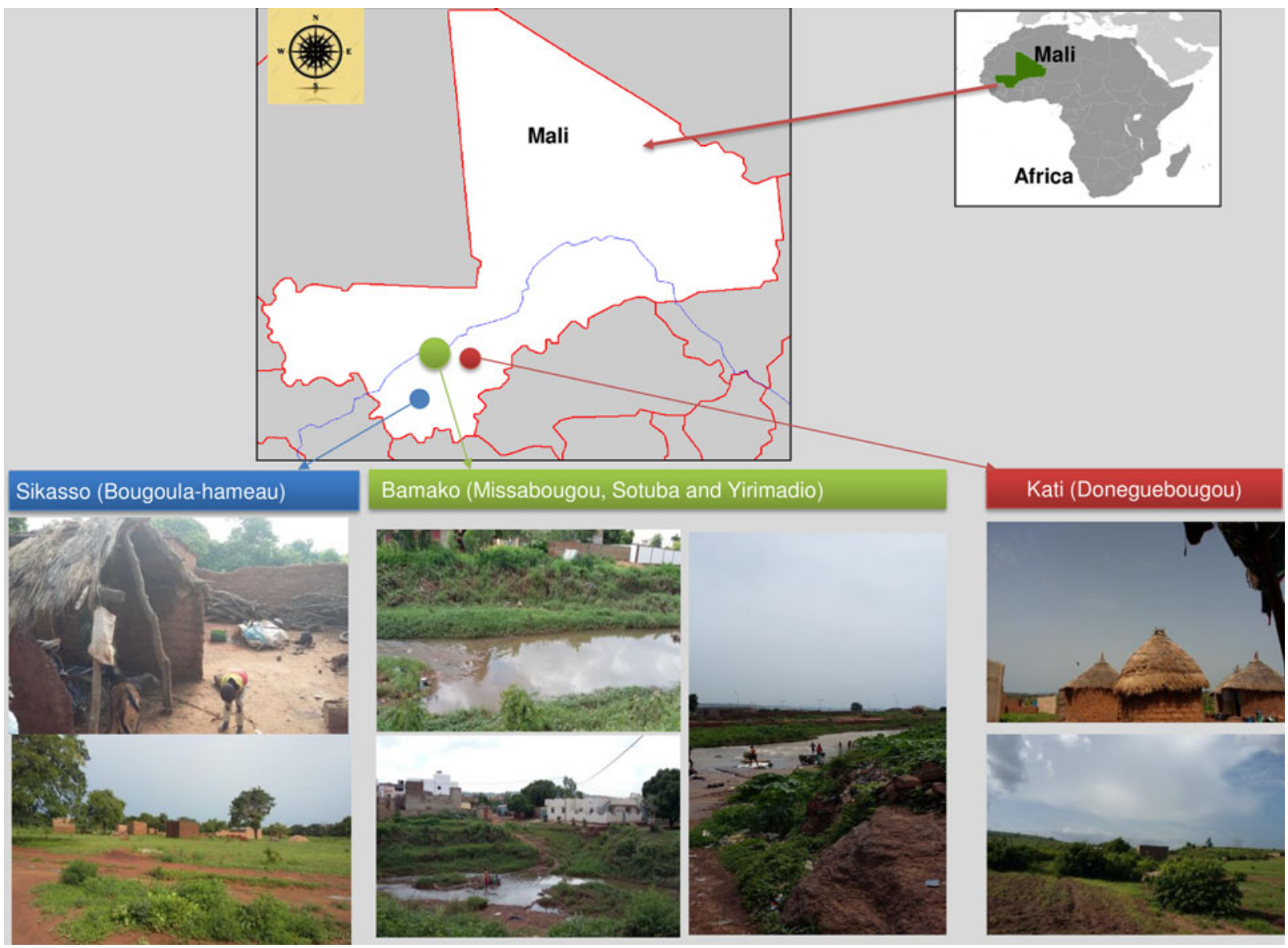

Fig. 1. Ecological patterns and geographic distribution of mosquito collection in Mali. Sikasso: Bougoula-hameau (rural area), Bamako: Sotuba (peri-urban area), Missabougou, Yirimadio (urban areas) and Kati: Doneguebougou (rural area). 


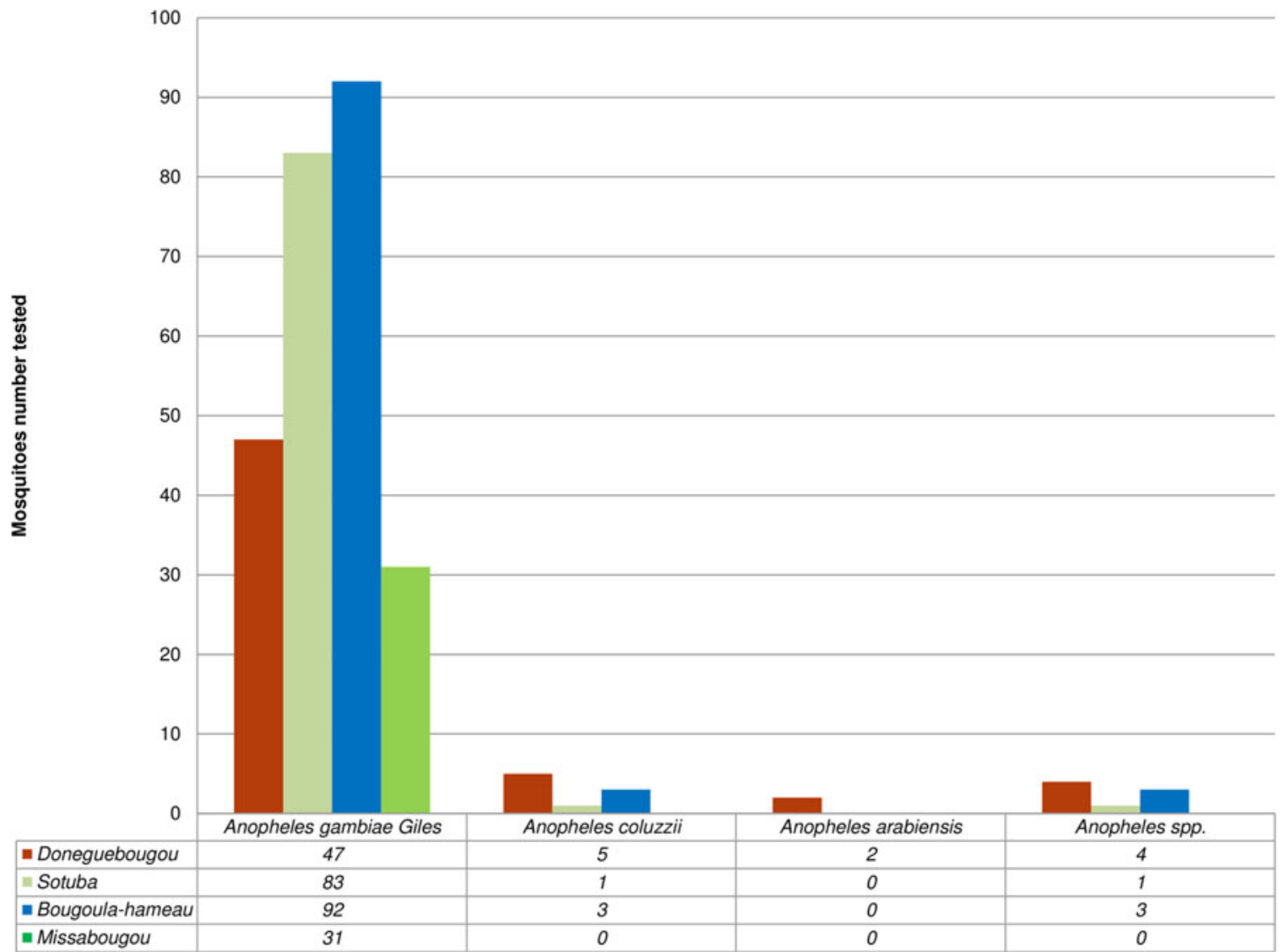

Fig. 2. MALDI-TOF MS Identification of 272 Anopheles spp. collected in Mali.

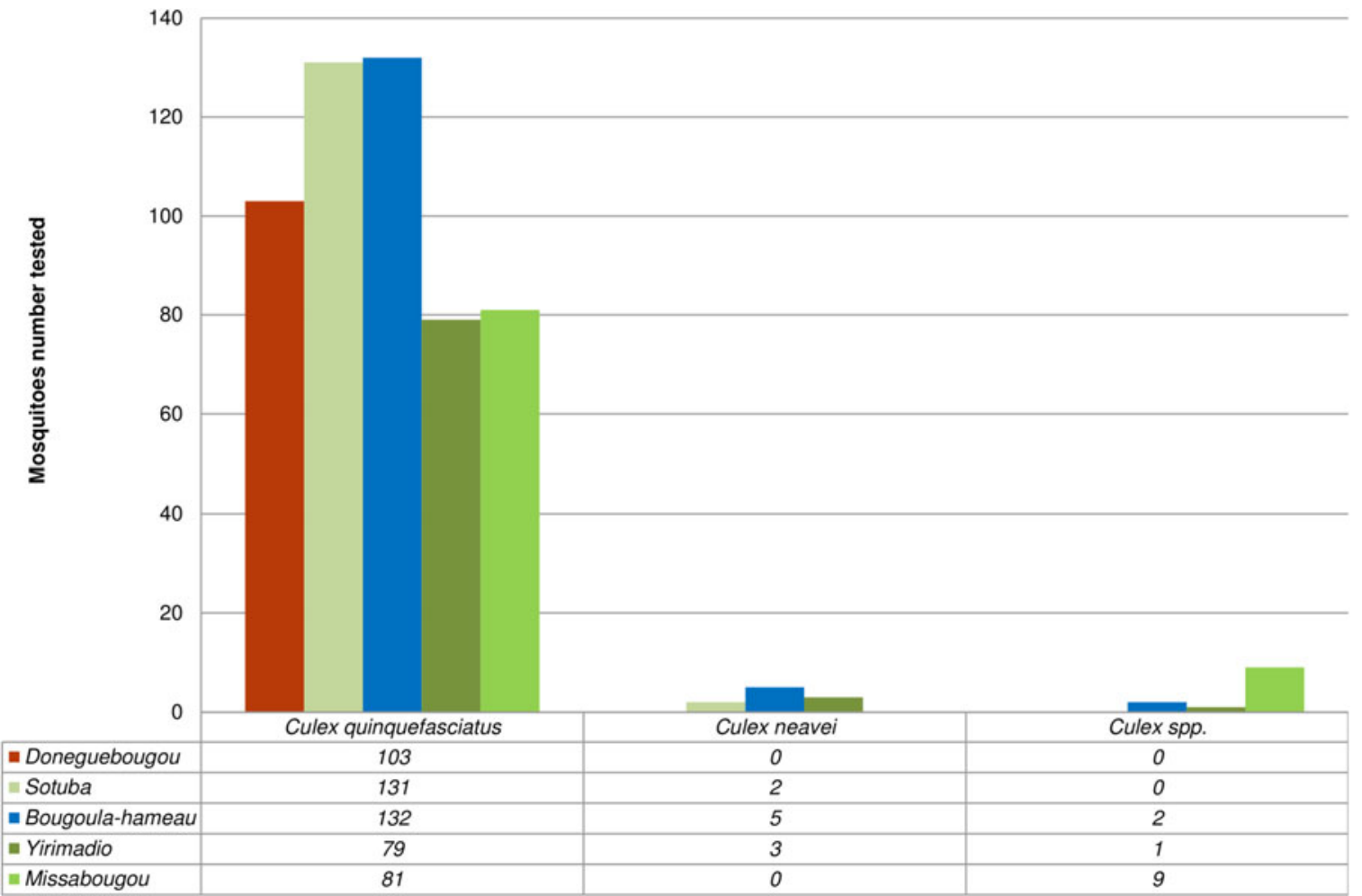

Fig. 3. MALDI-TOF MS Identification of 549 Culex spp. captured in Mali.

different species, namely Anopheles gambiae Giles, An. coluzzii, $A n$. arabiensis, Cx. quinquefasciatus, $C x$. neavei, Culex perexiguus, Ae. fowleri and Ae. aegypti. Clustering analysis of MSP spectra from two specimens per mosquito species was used to generate a dendrogram. Clustering analysis revealed a gathering on distinct branches, following the eight species which were loaded 
Fig. 4. Comparison of MALDI-TOF MS profiles of eight mosquito species collected in Mali. Spectra analysis was performed using Flex analysis 3.3 software. Abbreviations: a.u., arbitrary units; $m / z$, mass-to-charge ratio.

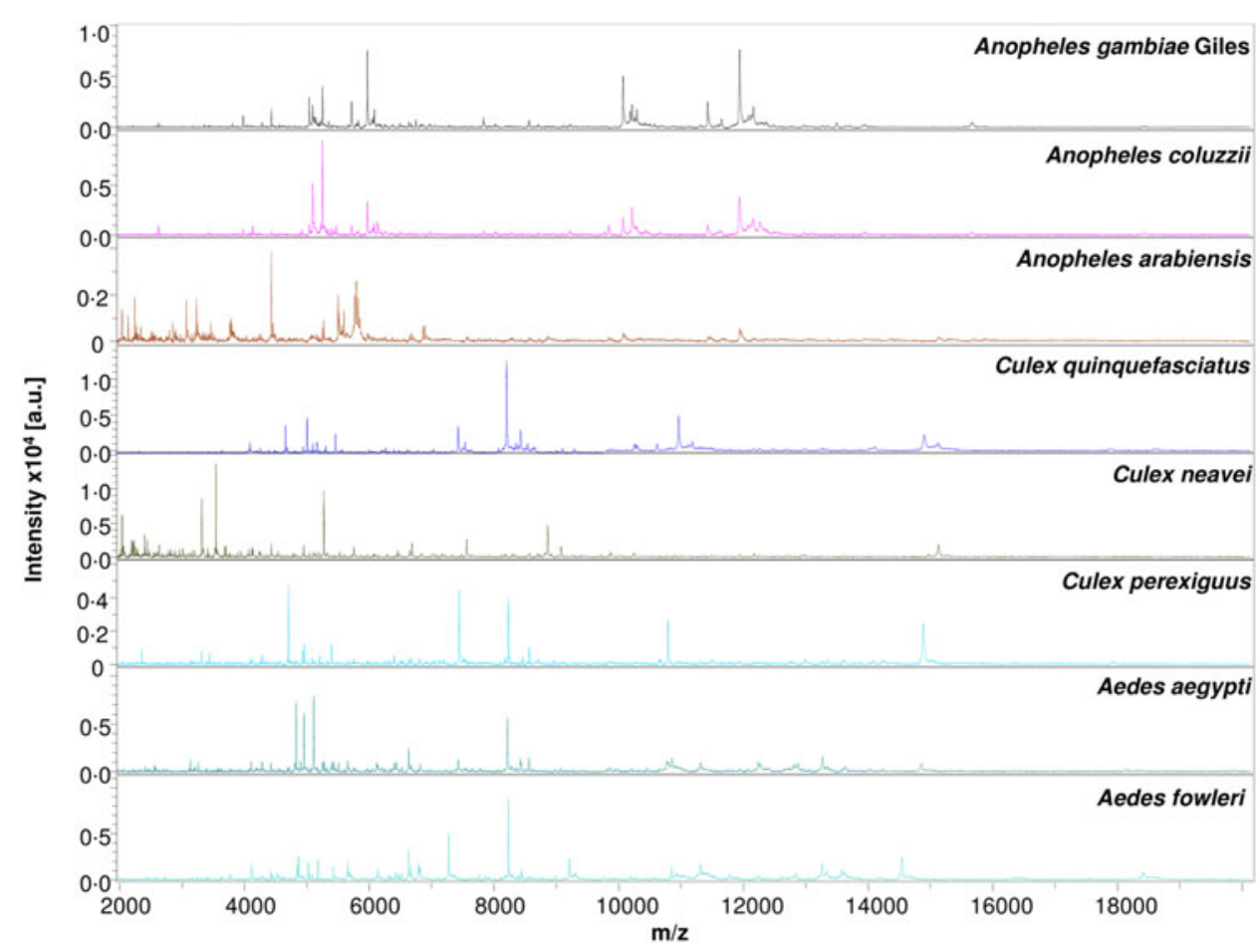

(Anopheles gambiae Giles, An. coluzzii, An. arabiensis, Cx. quinquefasciatus, Cx. neavei, Cx. perexiguus, Ae. fowleri and Ae. aegypti) (Fig. 5). The clusters formed were consistent with the intra-species reproducibility and inter-species specificity visually observed on protein profiles.

\section{Molecular identification of mosquitoes collected in Mali}

Molecular biology was performed to confirm the mosquito identification resulting from the MALDI-TOF MS analyses. For this purpose, we randomly selected 20/253 An. gambiae Giles, 2/9 An. coluzzii, 15/527 Cx. quinquefasciatus, 1/10 Cx. neavei for sequencing. The $28 S$ gene sequencing of Anopheles corroborated the MALDI-TOF MS identification in all cases, with between 97.51 and $99.27 \%$ identity with Genbank sequences (Table 2).

The acetylcholinesterase- 2 and COI genes were used to identify the Culex species. Sixteen specimens of $C x$. quinquefasciatus ( $n=$ $15)$ and $C x$. neavei $(n=1)$ were randomly selected for sequencing.
The molecular results were found to be highly consistent with the MALDI-TOF MS identification. Sequences obtained from $C x$. quinquefasciatus and $C x$. neavei were shown to share between 98.90 and $100 \%$ identity with Genbank (Table 2).

Molecular biology was also carried out on the mosquitoes that were not identified by MALDI-TOF MS (low scores), including the eight Anopheles spp. and 12 Culex spp. Sequencing of the $28 S$ gene was performed to identify the eight Anopheles spp. $(3 \%, n=8 / 264)$. The matching sequences corresponded to Anopheles gambiae Giles $(n=4)$ and An. coluzzii $(n=4)$, which were shown to share between 98.52 and $100 \%$ identity with Genbank (Table 2).

The acetylcholinesterase- 2 and COI genes were amplified to identify the 12 Culex spp. which were misidentified (2\%, $n=12$ / 549) by MALDI-TOF MS. The sequences obtained correspond to the $C x$. quinquefasciatus $(n=11)$ which were shown to share between 98.90 and $100 \%$ identity with Genbank and 100\% identity with $C x$. perexiguus $(n=1)$ (Table 2$)$.
Fig. 5. MSP (Main Spectrum Profile) dendrograms of MALDI-TOF MS spectra of eight mosquito species collected in Mali. Clustering analysis was performed using MALDI Biotyper software. Distance unit corresponds to the relative similarity calculated from the distance matrix.

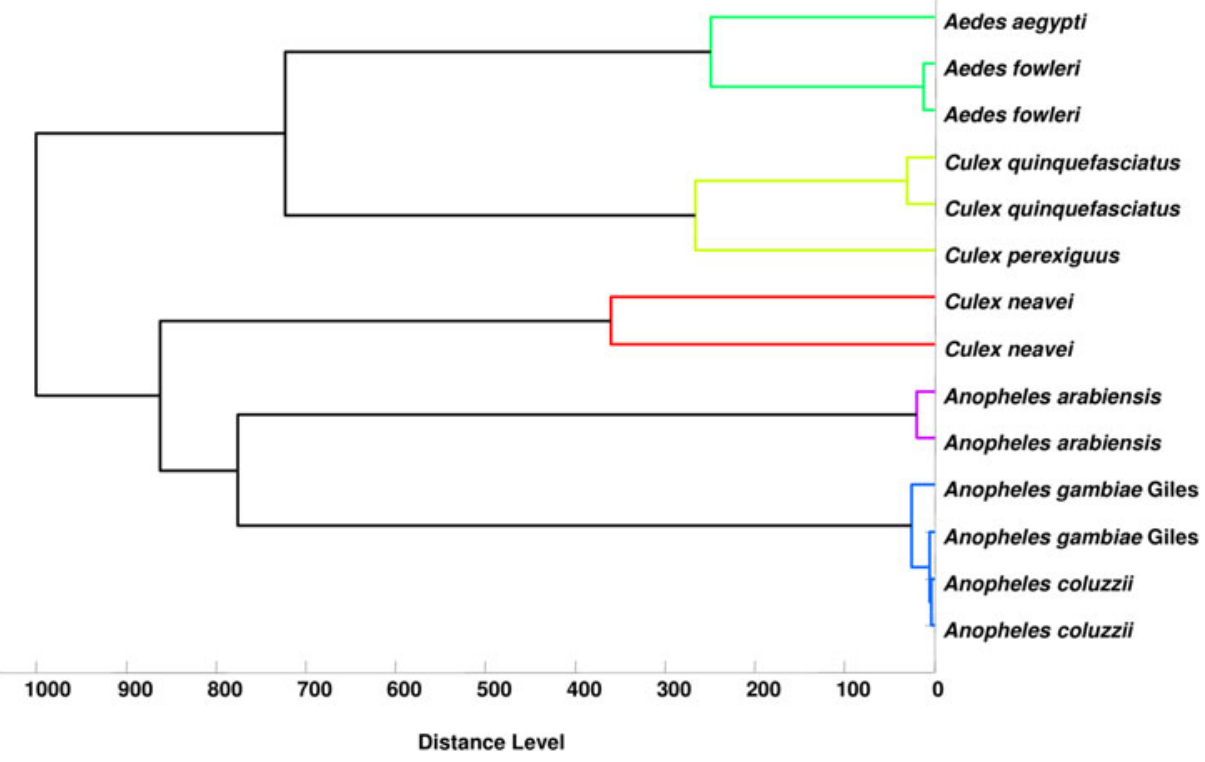


Table 2. Molecular identification of mosquitoes collected in Mali

\begin{tabular}{|c|c|c|c|c|c|c|c|}
\hline Collection sites & Morphological identification & MALDI-TOF MS identification & Log score value & Genes & Molecular identification & $\%$ Identities Genbank & Accession number \\
\hline Sotuba & Anopheles spp. & Human & {$[1.754]$} & $28 \mathrm{~S}$ & Anopheles coluzzii & 100 & AF470112.1 \\
\hline Donéguébougou & Anopheles spp. & Anopheles gambiae Giles & {$[2.470]$} & $28 \mathrm{~S}$ & Anopheles gambiae Giles & 99.25 & AF470116.1 \\
\hline Donéguébougou & Anopheles spp. & Human & [1.854] & $28 \mathrm{~S}$ & Anopheles coluzzii & 98.51 & AF470113.1 \\
\hline Donéguébougou & Anopheles spp. & Less relevant & [1.553] & $28 \mathrm{~S}$ & Anopheles coluzzii & 98.51 & AF470113.1 \\
\hline Donéguébougou & Anopheles spp. & Less relevant & [1.610] & $28 \mathrm{~S}$ & Anopheles coluzzii & 99.25 & KT284724.1 \\
\hline Donéguébougou & Anopheles spp. & Human & {$[2.008]$} & $28 \mathrm{~S}$ & Anopheles gambiae Giles & 98.14 & AF470116.1 \\
\hline Donéguébougou & Anopheles spp. & Anopheles coluzzii & {$[1.864]$} & $28 \mathrm{~S}$ & Anopheles coluzzii & 98.51 & AF470113.1 \\
\hline Bougoula -hameau & Anopheles spp. & Anopheles gambiae Giles & {$[2.383]$} & $28 \mathrm{~S}$ & Anopheles gambiae Giles & 98.88 & AF470116.1 \\
\hline Bougoula-hameau & Anopheles spp. & Anopheles gambiae Giles & {$[2.389]$} & 285 & Anopheles gambiae Giles & 99.25 & AF470115.1 \\
\hline Bougoula-hameau & Anopheles spp. & Anopheles gambiae Giles & {$[2.404]$} & $28 \mathrm{~S}$ & Anopheles gambiae Giles & 99.25 & AF470116.1 \\
\hline Bougoula-hameau & Anopheles spp. & Less relevant & {$[1.581]$} & $28 \mathrm{~S}$ & Anopheles gambiae Giles & 98.51 & AF470115.1 \\
\hline Bougoula-hameau & Anopheles spp. & Human & {$[2.286]$} & $28 \mathrm{~S}$ & Anopheles gambiae Giles & 98.88 & AF470115.1 \\
\hline Bougoula-hameau & Anopheles spp. & Human & [1.961] & $28 \mathrm{~S}$ & Anopheles gambiae Giles & 98.88 & AF470116.1 \\
\hline Bougoula-hameau & Anopheles spp. & Anopheles coluzzii & [1.964] & $28 \mathrm{~S}$ & Anopheles coluzzii & 98.51 & AF470113.1 \\
\hline Bougoula -hameau & Anopheles spp. & Anopheles gambiae Giles & {$[2.237]$} & $28 \mathrm{~S}$ & Anopheles gambiae Giles & 99.27 & AF470116.1 \\
\hline Bougoula -hameau & Anopheles spp. & Anopheles gambiae Giles & {$[2.406]$} & $28 \mathrm{~S}$ & Anopheles gambiae Giles & 99.27 & AF470116.1 \\
\hline Bougoula -hameau & Anopheles spp. & Anopheles gambiae Giles & {$[2.390]$} & $28 \mathrm{~S}$ & Anopheles gambiae Giles & 98.59 & AF470116.1 \\
\hline Missabougou & Anopheles spp. & Anopheles gambiae Giles & [2.099] & $28 \mathrm{~S}$ & Anopheles gambiae Giles & 99.27 & AF470116.1 \\
\hline Missabougou & Anopheles spp. & Anopheles gambiae Giles & {$[2.401]$} & $28 \mathrm{~S}$ & Anopheles gambiae Giles & 98.90 & AF470116.1 \\
\hline Missabougou & Anopheles spp. & Anopheles gambiae Giles & [2.283] & $28 \mathrm{~S}$ & Anopheles gambiae Giles & 98.54 & AF470116.1 \\
\hline Missabougou & Anopheles spp. & Anopheles gambiae Giles & {$[2.258]$} & $28 \mathrm{~S}$ & Anopheles gambiae Giles & 98.90 & AF470116.1 \\
\hline Missabougou & Anopheles spp. & Anopheles gambiae Giles & {$[2.368]$} & $28 \mathrm{~S}$ & Anopheles gambiae Giles & 98.91 & AF470116.1 \\
\hline Bougoula-hameau & Anopheles spp. & Anopheles gambiae Giles & [2.293] & $28 \mathrm{~S}$ & Anopheles gambiae Giles & 98.16 & AF470116.1 \\
\hline Bougoula-hameau & Anopheles spp. & Anopheles gambiae Giles & [2.293] & $28 \mathrm{~S}$ & Anopheles gambiae Giles & 98.13 & AF470116.1 \\
\hline Bougoula-hameau & Anopheles spp. & Anopheles gambiae Giles & [2.049] & $28 \mathrm{~S}$ & Anopheles gambiae Giles & 99.26 & AF470116.1 \\
\hline Bougoula-hameau & Anopheles spp. & Anopheles gambiae Giles & {$[2.311]$} & $28 \mathrm{~S}$ & Anopheles gambiae Giles & 97.51 & AF470116.1 \\
\hline Bougoula-hameau & Anopheles spp. & Anopheles gambiae Giles & {$[1.704]$} & $28 \mathrm{~S}$ & Anopheles gambiae Giles & 97.84 & AF470116.1 \\
\hline Bougoula-hameau & Anopheles spp. & Anopheles gambiae Giles & {$[2.110]$} & $28 \mathrm{~S}$ & Anopheles gambiae Giles & 98.50 & AF470116.1 \\
\hline Bougoula-hameau & Anopheles spp. & Anopheles gambiae Giles & {$[2.233]$} & $28 \mathrm{~S}$ & Anopheles gambiae Giles & 97.70 & AF470116.1 \\
\hline Donéguébougou & Anopheles spp. & Anopheles gambiae Giles & {$[2.204]$} & $28 \mathrm{~S}$ & Anopheles gambiae Giles & 98.13 & AF470116.1 \\
\hline Bougoula-hameau & Culex spp. & Culex pipiens & [2.022] & Ace2 & Culex quinquefasciatus & 99.26 & FJ416029.1 \\
\hline
\end{tabular}


Table 2. (Continued.)

\begin{tabular}{|c|c|c|c|c|c|c|c|}
\hline Collection sites & Morphological identification & MALDI-TOF MS identification & Log score value & Genes & Molecular identification & \% Identities Genbank & Accession number \\
\hline Bougoula-hameau & Culex spp. & Culex pipiens & [2.229] & Ace2 & Culex quinquefasciatus & 98.90 & FJ416029.1 \\
\hline Donéguébougou & Culex spp. & Culex quinquefasciatus & [1.791] & Ace2 & Culex quinquefasciatus & 99.26 & FJ416029.1 \\
\hline Missabougou & Culex spp. & Human & [2.182] & $\mathrm{COI}$ & Culex quinquefasciatus & 99.38 & KU920694.1 \\
\hline Missabougou & Culex spp. & Less relevant & {$[1.610]$} & $\mathrm{COI}$ & Culex perexiguus & 100 & KU380476.1 \\
\hline Missabougou & Culex spp. & Culex pipiens & {$[1.761]$} & Ace2 & Culex quinquefasciatus & 99.63 & FJ416025.1 \\
\hline Missabougou & Culex spp. & Human & [2.042] & $\mathrm{COI}$ & Culex quinquefasciatus & 99.08 & KU920694.1 \\
\hline Missabougou & Culex spp. & Culex pipiens & {$[2.139]$} & Ace2 & Culex quinquefasciatus & 98.90 & FJ416025.1 \\
\hline Missabougou & Culex spp. & Culex pipiens & [2.231] & Ace2 & Culex quinquefasciatus & 98.90 & FJ416025.1 \\
\hline Missabougou & Culex spp. & Human & [2.514] & $\mathrm{COI}$ & Culex quinquefasciatus & 99.84 & KU920694.1 \\
\hline Missabougou & Culex spp. & Culex pipiens & {$[2.088]$} & Ace2 & Culex quinquefasciatus & 98.90 & FJ416029.1 \\
\hline Missabougou & Culex spp. & Human & {$[2.294]$} & $\mathrm{COI}$ & Culex quinquefasciatus & 99.69 & KU920694.1 \\
\hline Yirimadio & Culex spp. & Culex pipiens & [2.032] & Ace2 & Culex quinquefasciatus & 98.90 & FJ416029.1 \\
\hline Donéguébougou & Culex spp. & Culex quinquefasciatus & {$[2.000]$} & Ace2 & Culex quinquefasciatus & 99.26 & FJ416029.1 \\
\hline Donéguébougou & Culex spp. & Culex quinquefasciatus & [2.009] & Ace2 & Culex quinquefasciatus & 99.27 & FJ416025.1 \\
\hline Donéguébougou & Culex spp. & Culex quinquefasciatus & {$[2.207]$} & Ace2 & Culex quinquefasciatus & 98.90 & FJ416025.1 \\
\hline Bougoula-hameau & Culex spp. & Culex quinquefasciatus & [2.406] & Ace2 & Culex quinquefasciatus & 98.90 & FJ416019.1 \\
\hline Bougoula-hameau & Culex spp & Culex neavei & {$[2.839]$} & $\mathrm{COI}$ & Culex neavei & 99.16 & KU380473.1 \\
\hline Bougoula-hameau & Culex spp & Culex quinquefasciatus & {$[2.037]$} & Ace2 & Culex quinquefasciatus & 99.11 & FJ416029.1 \\
\hline Bougoula-hameau & Culex spp & Culex quinquefasciatus & {$[2.197]$} & Ace2 & Culex quinquefasciatus & 99.55 & FJ416029.1 \\
\hline Bougoula-hameau & Culex spp & Culex quinquefasciatus & {$[2.146]$} & Ace2 & Culex quinquefasciatus & 99.56 & FJ416029.1 \\
\hline Bougoula-hameau & Culex spp & Culex quinquefasciatus & {$[2.383]$} & Ace2 & Culex quinquefasciatus & 99.56 & FJ416029.1 \\
\hline Bougoula-hameau & Culex spp & Culex quinquefasciatus & {$[2.322]$} & Ace2 & Culex quinquefasciatus & 99.13 & FJ416029.1 \\
\hline Donéguébougou & Culex spp. & Culex quinquefasciatus & {$[2.445]$} & Ace2 & Culex quinquefasciatus & 99.57 & FJ416029.1 \\
\hline Donéguébougou & Culex spp. & Culex quinquefasciatus & {$[2.067]$} & Ace2 & Culex quinquefasciatus & 98.71 & FJ416029.1 \\
\hline Donéguébougou & Culex spp. & Culex quinquefasciatus & {$[2.151]$} & Ace2 & Culex quinquefasciatus & 100 & FJ416029.1 \\
\hline Missabougou & Culex spp. & Culex quinquefasciatus & {$[2.244]$} & Ace2 & Culex quinquefasciatus & 98.68 & FJ416029.1 \\
\hline Missabougou & Culex spp. & Culex quinquefasciatus & [2.159] & Ace2 & Culex quinquefasciatus & 99.56 & FJ416029.1 \\
\hline
\end{tabular}

MALDI-TOF MS, matrix-assisted laser desorption/ionization time-of-flight mass spectrometry; Ace 2: acetylcholinesterase-2; COI: the cytochrome c oxidase; \%, per cent. 
Table 3. Identification of the blood meals of mosquitoes collected in distinct ecological areas in Mali

\begin{tabular}{|c|c|c|c|c|c|c|c|c|c|c|}
\hline \multirow[b]{2}{*}{ Sites } & \multirow[b]{2}{*}{ Morphological ID } & \multirow[b]{2}{*}{ Mosquito identified by MALDI-TOF MS } & \multicolumn{7}{|c|}{ Blood meals identified by MALDI-TOF MS } & \multirow[b]{2}{*}{ Tota } \\
\hline & & & Human & Chicken & Cow & Donkey & Dog & Sheep & Not identified & \\
\hline \multirow[t]{4}{*}{ Bougoula-hameau } & Anopheles & Anopheles gambiae Giles & 87 & & 3 & 5 & & & 3 & 98 \\
\hline & Anopheles & Anopheles coluzzii & 3 & & & & & & & 3 \\
\hline & Culex & Culex quinquefasciatus & 86 & 5 & & & 1 & & & 92 \\
\hline & Culex & Culex neavei & 3 & & & & & & & 3 \\
\hline \multirow[t]{4}{*}{ Donéguébougou } & Anopheles & Anopheles gambiae Giles & 46 & & 6 & 1 & & 2 & 4 & 59 \\
\hline & Anopheles & Anopheles coluzzii & 5 & & & & & & & 5 \\
\hline & Anopheles & Anopheles arabiensis & 2 & & & & & & & 2 \\
\hline & Culex & Culex quinquefasciatus & 93 & 1 & & & 1 & & 5 & 100 \\
\hline \multirow[t]{2}{*}{ Missabougou } & Anopheles & Anopheles gambiae Giles & 13 & & & & & & 2 & 15 \\
\hline & Culex & Culex quinquefasciatus & 69 & 1 & & & & & 12 & 82 \\
\hline \multirow[t]{3}{*}{ Sotuba } & Anopheles & Anopheles gambiae Giles & 51 & & & & 3 & 1 & 6 & 61 \\
\hline & Culex & Culex quinquefasciatus & 97 & & & & & & 2 & 99 \\
\hline & Culex & Culex neavei & 1 & & & & & & & 1 \\
\hline \multirow[t]{3}{*}{ Yirimadio } & Aedes & Aedes aegypti & 1 & & & & & & & 1 \\
\hline & Culex & Culex quinquefasciatus & 61 & 2 & & & & & 16 & 79 \\
\hline & Culex & Culex neavei & 1 & & & & & & & 1 \\
\hline Total & & & 619 & 9 & 9 & 6 & 5 & 3 & 50 & 701 \\
\hline
\end{tabular}

ID, Identification; MALDI-TOF MS, matrix-assisted laser desorption/ionization time-of-flight mass spectrometry. 


\section{Identification of the bloody WFPS sources by MALDI-TOF MS}

A total 701 abdomens of engorged mosquitoes were crushed in WFPs in the field in Mali. The 701 bloody BWFPs were submitted for MALDI-TOF MS analysis in Marseille one month after sampling. Of the 701 BWFPs, 651 (93\%) high-quality spectra were obtained. The 651 BWFPs MS high-quality spectra were queried against our blood source MALDI-TOF MS database for identification. They matched with spectra from our database, including those of mosquito abdomens engorged with human blood $(n=619)$, chicken blood $(n=9)$, cow blood $(n=9)$, donkey blood $(n=6), \operatorname{dog}$ blood $(n=5)$ and sheep blood $(n=3)$ (Table 3). These blood meals were identified using MALDI-TOF MS with log score values (LSVs) ranging from 1.707 to 2.731. The MS spectra comparison of different host blood revealed an intra-species reproducibility and an interspecies specificity by Flex analysis (Fig. 6).

\section{Molecular identification of the bloody mosquito WFPs}

A total of 41 bloody WFPs identified by MALDI-TOF MS as mosquito abdomens engorged with human blood $(n=21)$, donkey blood $(n=5)$, chicken blood $(n=4)$, cow blood $(n=5)$, dog blood $(n=4)$ and sheep blood $(n=2)$ were randomly selected for sequencing by COI gene amplification. Thirty-three bloody WFPs sequences were obtained which confirmed the accuracy of the MS identification. However, for eight bloody WFPs, no quality sequences could be obtained. The results of the PCR based on bloody WFP sequencing highly correlated with the results of MALDI TOF MS identification (Table 4). The sequences obtained from seventeen bloody WFPs had identities between 98.52 and 100\% against Genbank NCBI (Table 4).

\section{Discussion}

The goal of this work was not to provide precise data on the presence and abundance of various mosquito species in specific areas in Mali. Indeed, these data vary according to the type of climate and the seasons. However, we did want to test the usefulness of MALDI-TOF MS using mosquitoes collected in the field, as most preliminary studies have used laboratory specimens.

The use of MALDI-TOF MS has recently emerged in medical entomology, including for the identification of arthropods, their blood meals and the detection of potential microorganisms (Schaffner et al. 2014; Yssouf et al. 2016). The choice of the arthropod body part is critical for specimen identification by MALDI-TOF MS (Yssouf et al. 2016). For example, the legs from adult mosquitoes have been shown to be sufficient for identification, whereas whole specimens have been used for aquatic stages (larvae) (Nebbak et al. 2017).

Here, the MS spectra from mosquito legs collected in Mali, including 264 Anopheles, 549 Culex and five Aedes, permitted MALDI-TOF MS identification. The MS spectrum analyses from the mosquito legs revealed an intra-species reproducibility and inter-species specificity consistent with molecular validation (Fig. 5). Accurate identification of mosquitoes queried against the home-made MS database corresponded to $100 \%$ concordance with molecular identification results (Table 2). The consistent

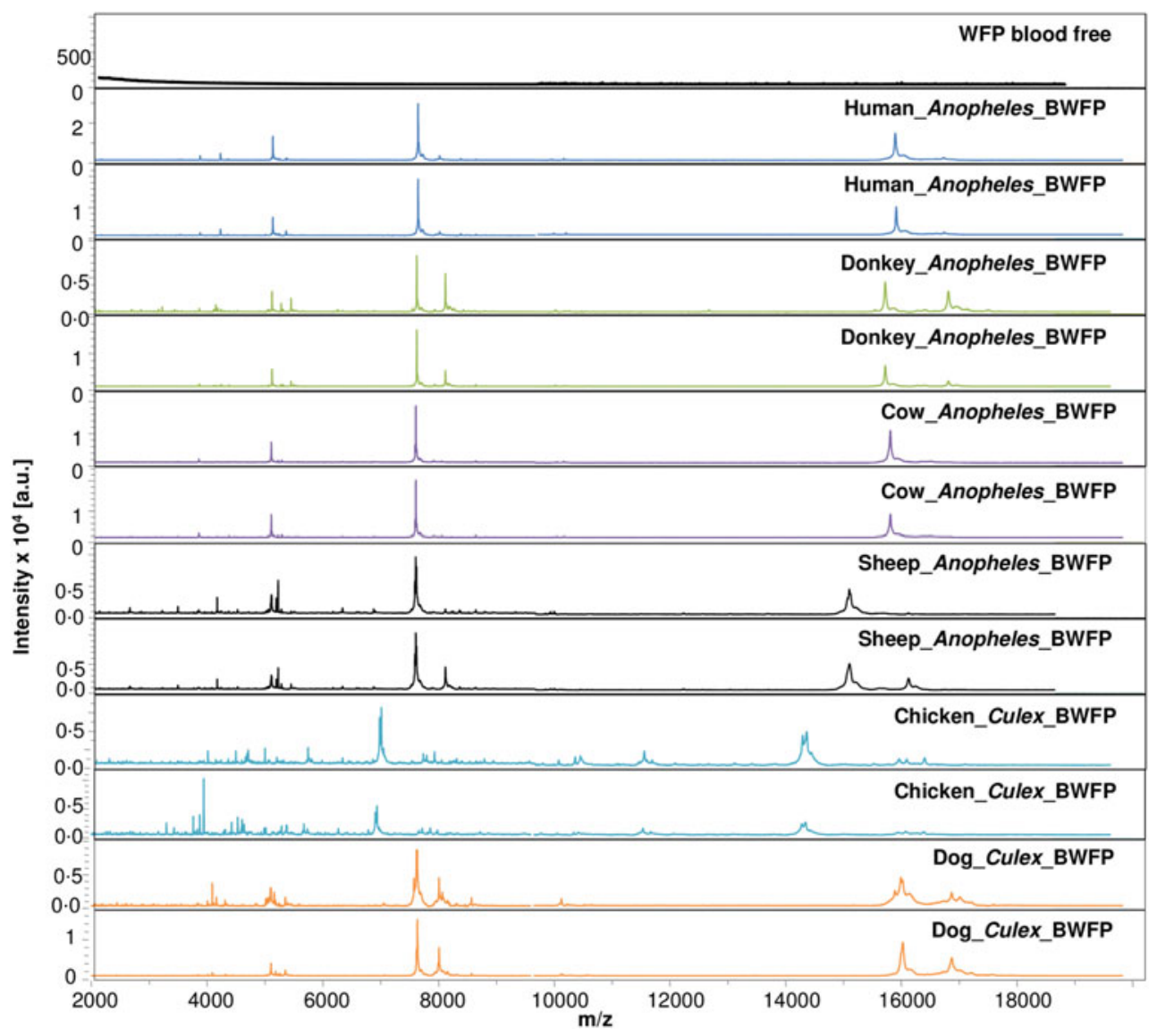

Fig. 6. The MS spectrum alignment from mosquito abdomen engorged on vertebrate host bloods and then crushed on Whatman filters. All bloody WFPs (BWFPs) were obtained from the field mosquitoes collected in Mali and crushed on WFPs. The MS spectrum alignment was performed by Flex analysis 3.3 software. The WFP blood free corresponds to the MS profiles of WFPs where no mosquito blood meal was released. The representative MS spectra from abdominal protein corresponds to Anopheles gambiae Giles abdomens BWFPs feed on human, donkey, cow and sheep blood, and Culex quinquefasciatus abdomens feed on chicken and dog blood. a.u. arbitrary units; $m / z$ mass-to-charge ratio. 
Table 4. Molecular identification of the blood from mosquito's abdomens crushed on Whatman filter papers

\begin{tabular}{|c|c|c|c|}
\hline $\begin{array}{l}\text { Mosquito blood } \\
\text { meals sources } \\
\text { identification } \\
\text { by MALDI-TOF } \\
\text { MS }\end{array}$ & $\begin{array}{l}\text { Mosquito blood } \\
\text { meals sources } \\
\text { identification by } \\
\text { COI gene } \\
\text { amplification }\end{array}$ & $\begin{array}{c}\% \\
\text { Identities } \\
\text { Genbank }\end{array}$ & $\begin{array}{c}\text { Accession } \\
\text { number } \\
\text { Genbank }\end{array}$ \\
\hline Human & Homo sapiens & 100 & KM102136.1 \\
\hline Human & Homo sapiens & 99.84 & KY595668.1 \\
\hline Human & Homo sapiens & 99.64 & HM185231.1 \\
\hline Human & Homo sapiens & 98.52 & KM102136.1 \\
\hline Human & Homo sapiens & 98.86 & KY595669.1 \\
\hline Human & Homo sapiens & 98.72 & MF058292.1 \\
\hline Human & Homo sapiens & 99.68 & KF161694.1 \\
\hline Human & Homo sapiens & 99.68 & MF058210.1 \\
\hline Human & Homo sapiens & 99.34 & MF058210.1 \\
\hline Human & Homo sapiens & 100 & MF058210.1 \\
\hline Human & Homo sapiens & 99.37 & MF058210.1 \\
\hline Human & Homo sapiens & 98.68 & MF058210.1 \\
\hline Human & Homo sapiens & 99.67 & MF058210.1 \\
\hline Human & Homo sapiens & 99.18 & AY275535.2 \\
\hline Human & Homo sapiens & 99.52 & MF588867.1 \\
\hline Human & Homo sapiens & 99.36 & MF057217.1 \\
\hline Human & Homo sapiens & 99.18 & MF588867.1 \\
\hline Human & Homo sapiens & 99.05 & AY922271.1 \\
\hline Human & Homo sapiens & 99.52 & MF588867.1 \\
\hline Human & Homo sapiens & 99.35 & KM101695.1 \\
\hline Human & Homo sapiens & 99.36 & KF163046.1 \\
\hline Donkey & Equus asinus & 99.37 & KX683425.1 \\
\hline Chicken & Gallus gallus & 99.68 & KX781318.1 \\
\hline Chicken & Gallus gallus & 99.22 & KX781318.1 \\
\hline Chicken & Gallus gallus & 99.21 & KX781318.1 \\
\hline Cow & Bos taurus & 99 & KY650678.1 \\
\hline Donkey & Equus asinus & 98.91 & KX683425.1 \\
\hline Cow & Failed & - & - \\
\hline Cow & Bos taurus & 99 & KY650678.1 \\
\hline Cow & Failed & - & - \\
\hline Cow & Failed & - & - \\
\hline Donkey & Failed & - & - \\
\hline Chicken & Gallus gallus & 98.52 & KX781318.1 \\
\hline Dog & Failed & - & - \\
\hline Dog & Failed & - & - \\
\hline Dog & Failed & - & - \\
\hline Donkey & Equus asinus & 99.52 & KX683425.1 \\
\hline Donkey & Equus asinus & 100 & KX683425.1 \\
\hline Sheep & Ovis aries & 99.84 & KP998473.1 \\
\hline Sheep & Ovis aries & 99.21 & KR868678.1 \\
\hline Dog & Failed & - & - \\
\hline
\end{tabular}

MALDI-TOF MS, matrix-assisted laser desorption/ionization time-of-flight mass spectrometry; $\mathrm{COI}$, the cytochrome $c$ oxidase; $\%$, per cent. identification between molecular biology and MALDI-TOF MS was validated by the choice of the $28 S$ gene for Anopheles species identification, and the acetylcholinesterase- 2 and COI genes for Culex species identification. As shown in previous studies, the choice of these genes was highly relevant to discriminate and assess the phylogenetic relation between different mosquito species (Folmer et al. 1994; Fanello et al. 2002; Smith and Fonseca, 2004). Here, the quality of spectra was a very important element for identification, as more than $98 \%$ of the good quality spectra were identified with LSVs $>1.8$. The MALDI-TOF MS reference database has been updated with other mosquito species. It is necessary to create a reference database, which could subsequently be shared, and open access could be provided for routine arthropod identification. In this study, Aedes mosquitoes collected in Mali were correctly identified as Ae. fowleri using a database containing reference spectra of this species collected from La Reunion Island only, which is located in the Pacific Ocean. Therefore MALDI-TOF MS appears as an efficient tool for the identification of arthropods collected from distant geographical areas.

For Raharimalala et al. (2017), the usefulness and accuracy of MALDI-TOF MS as a tool to identify vector mosquito species requires the creation of an international database (Raharimalala et al. 2017). In this study, $2.40 \%$ of inconsistent MS leg results were attributed to low-quality MS spectra for identification. The MS spectra of some legs $(n=9)$ (Table 2) that matched with reference spectra of mosquito abdomens engorged with human blood were attributed to traces of blood on the legs during the abdomen crushing process onto WFPs. This phenomenon of lowquality spectra, leading to lower identification rates have been reported in arthropod identification such as at the aquatic mosquito stage (Dieme et al. 2014). According to the reproducibility of MS spectra, the hierarchical clustering showed that all specimens from the same species were grouped in the same branch. These results are similar to previous studies supporting interspecies reproducibility for mosquito identification (Yssouf et al. 2013). Additionally, we stress that MS cannot yet be considered a reliable tool for the phylogenetic study of mosquito species (Yssouf et al. 2013).

Our results showed that $95 \%$ of the collected mosquitoes had fed on human blood. This result is not surprising because all mosquitoes were collected inside homes. The advantage of our MALDI-TOF approach is its rapidity, effectiveness and reliability in determining bloody WFPs, since more than 100 bloody WFPs specimens were processed per day. Previously, the authors had demonstrated that the profiles of abdominal spectra of mosquito females engorged on human blood are the same, regardless of whether they were crushed or not crushed on WFPs (Niare et al. 2017). Indeed, the home-made database contains filter papers with Anopheles gambiae engorged blood such as human blood and sheep blood. These authors tested WFP either with the crushed abdomen of a non-engorged mosquito or simply as a control (Niare et al. 2017). These results suggest that MALDITOF MS is not time-consuming in comparison with molecular tools and serological techniques. The eight bloody WFPs which failed molecular biology identification may be attributed to blood meal digestion. As previously reported, the time of the host blood digestion in the mosquito has an impact upon blood meal identification by MALDI-TOF MS and molecular biology (Niare et al. 2016). Moreover, the molecular biology results of the seventeen BWFPs sequences obtained by COI gene amplification corroborated the MALDI-TOF MS identification (Table 4).

Interestingly, as we have recently found that MALDI-TOF may also recognize mixed blood meals (unpublished), we did not find any mixed blood meals either by molecular tools nor by MALDI-TOF. The authors experimentally engorged An. gambiae Giles mosquitoes with a mixture of blood from distinct vertebrate 
hosts, such as human, sheep and dogs. Their results demonstrate that mixed mosquito blood meals can be successfully identified, depending on the concentration ratio (unpublished). Recently, some authors have also used the proteomic approach to identify the sources of tick mixed blood meals (Onder et al. 2013).

Of the mosquitoes identified by MALDI-TOF MS, A. gambiae Giles and $C x$. quinquefasciatus were widely distributed across all collection sites. Our work enabled $C x$. neavei and $C x$. perexiguus to be detected for the first time in Mali. Currently, few studies have been carried out on the Culex species in Mali, particularly on their abundance, ecology and the infectious pathogens transmitted by these vectors. Culex species are widely distributed in West Africa and are found in any type of breeding sites (clear and polluted water), whereas the Anopheles species colonizes sunny, fresh water (Becker et al. 2010). There is an abundant literature on these mosquitoes, the well-known distribution of $C x$. neavei and $C x$. perexiguus in sub-Saharan Africa and their implication in the transmission of many arboviruses (Jupp et al. 1986; Fyodorova et al. 2006; Nikolay et al. 2012; Fall et al. 2014; Gould et al. 2017). The presence of these potential vectors in Mali might be of epidemiological importance.

Our study is the first to use MALDI-TOF MS as a tool for monitoring field mosquitoes in Africa, particularly in Mali, an endemic malarial area. Moreover, when the MALDI-TOF MS device is bought for clinical microbiology purposes, it can also be used for medical entomology at no additional cost. For example, at the Dakar hospital in Senegal, the MALDI-TOF MS equipment that was initially bought for clinical microbiology has been used for field entomology surveys and has successfully identified Culicoides (Sambou et al. 2015). In Senegal, the acquisition of MALDI-TOF MS equipment has revolutionized bacteriology laboratories and clinical microbiology domains, suggesting that this technique can be used as a front-line tool in tropical countries (Lo et al. 2015).

Although the time period for blood meal source determination by MALDI-TOF MS was shorter than that of molecular biology or ELISA, the rapidity and low cost of the reagents made this proteomic method a financial and reliable competitive strategy. However, the relatively high cost of the machine could be an impediment to implementation of this innovative tool in laboratories. The cost of purchasing the MALDI-TOF MS equipment in under-developed countries such as Mali (sub-Saharan Africa) could be a limitation to estimating the local vector-borne risk. However, when the device is bought by a microbiology lab it can be used in medical entomology at no additional cost.

\section{Concluding remarks}

The present study successfully identified field mosquitoes and the sources of their blood meals using MALDI-TOF MS. The mosquitoes collected in Mali were correctly identified based on reproducibility and specificity from the protein profiles of leg extracts. The innovative MALDI-TOF MS tool enabled the rapid identification of eight mosquito species in Mali during entomological surveys. The challenge is to maintain and develop collaboration between north and south to facilitate the acquisition of the MALDI-TOF MS equipment.

Acknowledgements. We thank all members of the various MRTC sites where mosquitoes were collected. We would also like to acknowledge all the residents of the various concessions where we captured mosquitoes.

Competing interests. The authors declare that they have no competing interests.
Author contributions. PP, TF and NS designed and developed the protocol. TF and NS performed the protocol. PP, TF, NS and ML analysed the data. KKA, DZA, OA, BMJ, OD and RD contributed reagents/materials/analysis tools. PP, TF and NS wrote the paper. OD and RD contributed to editing the paper. All authors agreed to publication.

Financial support. The project has received funding from the Excellence Initiative of Aix-Marseille University - $A^{\star}$ MIDEX, a French 'Investissements d'Avenir' program (No. ANR-11-IDEX-0001-02) and grants from the Malian Minister of Health, the Foundation Mérieux, UMI3189, and the Malian Research and Training Center (MRTC) for the field specimen collection.

\section{References}

Anosike JC, Nwoke BE, Ajayi EG, Onwuliri CO, Okoro OU, Oku EE, Asor JE, Amajuoyi OU, Ikpeama CA, Ogbusu FI and Meribe CO (2005) Lymphatic filariasis among the Ezza people of Ebonyi state, Eastern Nigeria. Annals of Agricultural and Environnemental Medicine 12, 181-186.

Bass C, Williamson MS, Wilding CS, Donnelly MJ and Field LM (2007) Identification of the main malaria vectors in the Anopheles gambiae species complex using a TaqMan real-time PCR assay. Malaria Journal 6, 155.

Becker N, Petriæ D, Zgomba M, Boase C, Dahl C, Madon M and Kaiser A (2010) Mosquitoes and Their Control, 2nd Edn. Heidelberg, Germany: Springer.

Brasil P, Zalis MG, de Pina-Costa A, Siqueira AM, Junior CB, Silva S, Areas ALL, Pelajo-Machado $M$, de Alvarenga DAM, da Silva Santelli ACF, Albuquerque HG, Cravo P, Santos de Abreu FV, Peterka CL, Zanini GM, Suarez Mutis MC, Pissinatti A, Lourenco-de-Oliveira R, de Brito CFA, de Fatima Ferreira-da-Cruz, Culleton R and Daniel-Ribeiro CT (2017) Outbreak of human malaria caused by Plasmodium simium in the Atlantic forest in Rio de Janeiro: a molecular epidemiological investigation. Lancet Global Health 5, 1038-1046.

Caglioti C, Lalle E, Castilletti C, Carletti F, Capobianchi MR and Bordi L (2013) Chikungunya virus infection: an overview. New Microbiology 36, 211-227.

de Wispelaere M, Despres P and Choumet V (2017) European Aedes albopictus and Culex pipiens Are competent vectors for Japanese encephalitis virus. PLoS Neglected Tropical Diseases 11, e0005294.

Dieme C, Yssouf A, Vega-Rua A, Berenger JM, Failloux AB, Raoult D, Parola P and Almeras L (2014) Accurate identification of Culicidae at aquatic developmental stages by MALDI-TOF MS profiling. Parasites \&Vectors 7, 544.

Fall G, Diallo M, Loucoubar C, Faye O and Sall AA (2014) Vector competence of Culex neavei and Culex quinquefasciatus (Diptera: Culicidae) from Senegal for lineages 1,2 , koutango and a putative new lineage of west Nile virus. American Journal of Tropical Medicine and Hygiene 90, 747-754.

Fanello C, Santolamazza F and della TA, (2002) Simultaneous identification of species and molecular forms of the Anopheles gambiae complex by PCR-RFLP. Medical and Veterinary Entomology 16, 461-464.

Folmer O, Black M, Hoeh W, Lutz R and Vrijenhoek R (1994) DNA primers for amplification of mitochondrial cytochrome $\mathrm{c}$ oxidase subunit I from diverse metazoan invertebrates. Molecular Marine Biology and Biotechnology 3, 294-299.

Fyodorova MV, Savage HM, Lopatina JV, Bulgakova TA, Ivanitsky AV, Platonova OV and Platonov AE (2006) Evaluation of potential west Nile virus vectors in volgograd region, Russia, 2003 (Diptera: Culicidae): species composition, bloodmeal host utilization, and virus infection rates of mosquitoes. Journal of Medical Entomology 43, 552-563.

Gardner CL and Ryman KD (2010) Yellow fever: a reemerging threat. Clinics in Laboratory Medicine 30, 237-260.

Gillies MT and Coetzee M (1987) A supplement to the Anophelinae of Africa south of the Sahara. South African Institute for Medical Research 55, 143p.

Gomes B, Sousa CA, Vicente JL, Pinho L, Calderon I, Arez E, Almeida AP, Donnelly MJ and Pinto J (2013) Feeding patterns of molestus and pipiens forms of Culex pipiens (Diptera: Culicidae) in a region of high hybridization. Parasites \& Vectors 6, 93.

Gould E, Pettersson J, Higgs S, Charrel R and de Lamballerie X (2017) Emerging arboviruses: why today? One Health 4, 1-13.

Jupp PG, McIntosh BM and Blackburn NK (1986) Experimental assessment of the vector competence of Culex (Culex) neavei theobald with west Nile 
and sindbis viruses in South Africa. Transactions of the Royal Society of Tropical Medicine and Hygiene 80, 226-230.

Komar N (2003) West Nile virus: epidemiology and ecology in North America. Advances in Virus Research 61, 185-234.

Kumsa B, Laroche M, Almeras L, Mediannikov O, Raoult D and Parola P (2016) Morphological, molecular and MALDI-TOF mass spectrometry identification of ixodid tick species collected in Oromia, Ethiopia. Parasitology Research 115, 4199-4210.

Lafri I, Almeras L, Bitam I, Caputo A, Yssouf A, Forestier CL, Izri A, Raoult D and Parola P (2016) Identification of Algerian field-caught phlebotomine sand Fly vectors by MALDI-TOF MS. PLoS Neglected Tropical Diseases 10, e0004351.

Lo CI, Fall B, Sambe-Ba B, Diawara S, Gueye MW, Mediannikov O, Sokhna C, Faye N, Dieme Y, Wade B, Raoult D and Fenollar F (2015) MALDI-TOF Mass spectrometry: a powerful tool for clinical microbiology at hopital principal de Dakar, Senegal (West Africa). PLoS ONE 10, e0145889.

Muturi EJ, Mwangangi JM, Beier JC, Blackshear M, Wauna J, Sang R and Mukabana WR (2013) Ecology and behavior of Anopheles arabiensis in relation to agricultural practices in central Kenya. Journal of the American Mosquito Control Association 29, 222-230.

Nebbak A, Willcox AC, Bitam I, Raoult D, Parola P and Almeras L (2016) Standardization of sample homogenization for mosquito identification using an innovative proteomic tool based on protein profiling. Proteomics 16, 3148-3160.

Nebbak A, Koumare S, Willcox AC, Raoult D, Almeras L and Parola P (2017) Field application of MALDI-TOF MS on mosquito larvae identification. Parasitology 3, 1-11.

Niare S, Berenger JM, Dieme C, Doumbo O, Raoult D, Parola $P$ and Almeras L (2016) Identification of blood meal sources in the main African malaria mosquito vector by MALDI-TOF MS. Malariar Journal 15, 87.

Niare S, Almeras L, Tandina F, Yssouf A, Bacar A, Toilibou A, Doumbo O, Raoult D and Parola P (2017) MALDI-TOF MS identification of Anopheles gambiae giles blood meal crushed on Whatman filter papers. PLoS One 12, e0183238.

Nikolay B, Diallo M, Faye O, Boye CS and Sall AA (2012) Vector competence of Culex neavei (Diptera: Culicidae) for usutu virus. American Journal of Tropical Medicine and Hygiene 86, 993-996.

Onder O, Shao W, Kemps BD, Lam H and Brisson D (2013) Identifying sources of tick blood meals using unidentified tandem mass spectral libraries. Nature Communication 4, 1746.

Raharimalala FN, Andrianinarivomanana TM, Rakotondrasoa A Collard JM and Boyer S (2017) Usefulness and accuracy of MALDI-TOF mass spectrometry as a supplementary tool to identify mosquito vector species and to invest in development of international database. Medical and Veterinary Entomology 31, 289-298.
Sambou M, Aubadie-Ladrix M, Fenollar F, Fall B, Bassene H, Almeras L, Sambe-Ba B, Perrot N, Chatellier S, Faye N, Parola P, Wade B, Raoult D and Mediannikov O (2015) Comparison of matrix-assisted laser desorption ionization-time of flight mass spectrometry and molecular biology techniques for identification of culicoides (Diptera: Ceratopogonidae) biting midges in Senegal. Journal of Clinical Microbiology 53, 410-418.

Schaffner F, Kaufmann C, Pfluger V and Mathis A (2014) Rapid protein profiling facilitates surveillance of invasive mosquito species. Parasites \& Vectors 7, 142.

Smith JL and Fonseca DM (2004) Rapid assays for identification of members of the Culex (Culex) pipiens complex, their hybrids, and other sibling species (Diptera: Culicidae). American Journal of Tropical Medicine and Hygiene 70, 339-345.

Sogoba N, Doumbia S, Vounatsou P, Baber I, Keita M, Maiga M, Traore SF, Toure A, Dolo G, Smith T and Ribeiro JM (2007) Monitoring of larval habitats and mosquito densities in the Sudan Savanna of Mali: implications for malaria vector control. American Journal of Tropical Medicine and Hygiene 77, 82-88.

Vasilakis N, Cardosa J, Hanley KA, Holmes EC and Weaver SC (2011) Fever from the forest: prospects for the continued emergence of sylvatic dengue virus and its impact on public health. Nature Reviews Microbiology 9, $532-541$.

WHO (1992) Entomological Field Techniques for Malaria Control. Part I, Learners Guide. Geneva: World Health Organization.

WHO (2016) World Malaria Report 2016. Geneva: World Health Organization.

Yssouf A, Socolovschi C, Flaudrops C, Ndiath MO, Sougoufara S, Dehecq JS, Lacour G, Berenger JM, Sokhna CS, Raoult D and Parola P (2013) Matrix-assisted laser desorption ionization-time of flight mass spectrometry: an emerging tool for the rapid identification of mosquito vectors. PLoS ONE 8, e72380.

Yssouf A, Parola P, Lindstrom A, Lilja T, L'Ambert G, Bondesson U, Berenger JM, Raoult D and Almeras L (2014a) Identification of European mosquito species by MALDI-TOF MS. Parasitology Research 113, 2375-2378

Yssouf A, Socolovschi C, Leulmi H, Kernif T, Bitam I, Audoly G, Almeras L, Raoult D and Parola P (2014b) Identification of flea species using MALDI-TOF/MS. Comparative Immunology, Microbiology and Infectious Diseases 37, 153-157.

Yssouf A, Almeras L, Berenger JM, Laroche M, Raoult D and Parola P (2015) Identification of tick species and disseminate pathogen using hemolymph by MALDI-TOF MS. Ticks and Tick-Borne Diseases 6, 579-586.

Yssouf A, Almeras L, Raoult D and Parola P (2016) Emerging tools for identification of arthropod vectors. Future Microbiology 11, 549-566. 